\title{
METHODS TO DETECT AND PREVENT FATIGUE IN AGEING AIRCRAFT STRUCTURES
}

\author{
Željko Marušić, Dajana Bartulović, Branko Maković
}

Subject review

The paper is focused on the methods which detect and prevent material fatigue in ageing aircraft structures. The goal is to analyse material fatigue and its impact on aircraft structures. The significance and impact of fatigue is given in description of accidents that were caused directly by material fatigue of the aircraft structures. The most important and most commonly used methods to detect and prevent fatigue in aircraft structures are infinite lifetime concept methods, finite lifetime concept methods, non-destructive testing methods, cold expansion methods, built-in testing equipment, structural health monitoring methods and methods to detect corrosion fatigue.

Keywords: accidents; ageing aircraft; fatigue failures; material fatigue; methods

Metode otkrivanja i sprječavanja zamora materijala u zrakoplovnoj strukturi

Pregledni članak Rad je usmjeren na metode koje mogu otkriti i spriječiti zamor materijala i starenje zrakoplovnih struktura. Cilj rada je analizirati zamor materijala $\mathrm{i}$ njegov utjecaj na strukture zrakoplova. Utjecaj i značaj zamora je istaknut u opisima nesreća koje su uzrokovane izravno zamorom materijala zrakoplovnih struktura. Najvažnije i najčešće korištene metode za otkrivanje i sprječavanje zamora materijala u strukturama zrakoplova su metode koncepta beskonačnog životnog vijeka, metode koncepta konačnog životnog vijeka, ne-destruktivne metode ispitivanja, metode hladne ekspanzije, metode testiranja ugrađenom opremom, metode praćenja stanja zrakoplovne strukture i metode otkrivanja korozije koja uzrokuje zamor materijala.

Ključne riječi: metode; nesreće; otkazi radi zamora materijala; starenje zrakoplova; zamor materijala

\section{Introduction}

The focus of this paper is material fatigue of aircraft structures and methods that can effectively detect and prevent further impact of fatigue on aircraft structure, and ultimately prevent disasters from happening.

Fatigue is the weakening of a material caused by repeatedly applied loads. It is progressive and localized structural damage that occurs when a material is subjected to cyclic loading. The nominal maximum stress values that cause such damage may be much less than the strength of the material.

Hence, fatigue occurs when a material is subjected to frequent loading and unloading. If the loads are above a certain threshold, microscopic cracks will begin to form at the stress concentrators such as the surface. Eventually a crack will reach a critical size, it will propagate suddenly, and the structure will fracture.

The shape of the structure significantly affects the fatigue life; square holes or sharp corners lead to elevated local stresses where fatigue cracks can initiate. Round holes and smooth transitions or fillets therefore increase the fatigue strength of the structure.

Intensive development of air traffic in early 1930s was followed by the regulations on resources for aircraft engines. The first maintenance systems based on the previous experiences were built according to the model of preventive maintenance with pre-defined resources (Hard Time Limit).

Because of this kind of maintenance, unnecessary dismantling of engines and assemblies often took place, and also there was considerable properly operating remaining resource left behind. It is known that the intensity of ageing depends on the manner and conditions of exploitation which are highly variable. This way of maintenance increased maintenance costs and decreased overall efficiency of the airline operators.
After the World War Second a new system of maintenance (On Condition) is developed. It was also a type of preventative maintenance. The systems are tested in a given time in order to assess the situation and, if necessary, take corrective actions to prevent the occurrence of function failures during operation.

In the early sixties maintenance systems are developed and based on reliability programs (Reliability Centred Maintenance). It is a methodology (set of rules) to prevent failures. It results in the identification of the required type (or policy) of maintenance that needs to be applied to individual failures. It also enables the development of sensor technology and continuous monitoring of system status (Condition Monitoring).

\section{Accidents and fatigue failures}

Accidents caused by fatigue and similar causes are presented below.

In 1948 Northwest Airlines Flight 421 crashed due to fatigue failure in a wing spar root.

In 1954 British Overseas Airways Corporation Flight 781, a De Havilland Comet 1 registered G-ALYP, suffered an explosive decompression at altitude and crashed into the Mediterranean Sea, killing everyone on board. The cause was in-flight metal fatigue failure leading to explosive decompression and mid-air breakup.

In 1954 South African Airways Flight 201, a De Havilland Comet 1 crashed, killing all aboard. The cause was in-flight metal fatigue failure leading to explosive decompression and breakup.

In 1957 "Mt. Pinatubo", a presidential plane of Philippine President Ramon Magsaysay crashed due to engine failure caused by metal fatigue.

In 1968 Los Angeles Airways Flight 417 lost one of its main rotor blades due to fatigue failure. 
In 1968 MacRobertson Miller Airlines Flight 1750 lost a wing due to improper maintenance what led to fatigue failure.

In 1977 Dan-Air Boeing 707 crashed, caused by fatigue failure resulting in the loss of the right horizontal stabilizer.

In 1980 LOT Flight 7 crashed due to fatigue in an engine turbine shaft resulting in engine disintegration leading to loss of control.

In 1985 Japan Airlines Flight 123 crashed after the aircraft lost its vertical stabilizer due to faulty repairs on the rear bulkhead.

In 1988 Aloha Airlines Flight 243 suffered an explosive decompression due to fatigue failure.

In 1989 United Airlines Flight 232 lost its tail engine due to fatigue failure in a fan disk hub.

In $1992 \mathrm{El} \mathrm{Al} \mathrm{Flight} 1862$ lost both engines on its right-wing due to fatigue failure in the pylon mounting of the engine.

In 2002 China Airlines Flight 611 disintegrated in flight due to fatigue failure.

In 2005 Chalk's Ocean Airways Flight 101 lost its right wing due to fatigue failure caused by inadequate maintenance practices.

De Havilland Comet 1 aircraft accidents were a "wake up call" to the catastrophic effects of material fatigue. At the beginning of the jet transport age, material fatigue was recognized as a serious problem in aircraft structures.

\section{Methods to detect and prevent fatigue of material}

Different methods are developed to detect and prevent fatigue of material in aircraft structures. The most important and most commonly used methods are discussed in this paper. Those methods are infinite lifetime concept methods, finite lifetime concept methods, non-destructive testing methods, cold expansion methods, methods using built-in testing equipment and structural health monitoring methods.

\subsection{Infinite lifetime concept methods}

Infinite lifetime concept is a design to keep stress below threshold of fatigue limit. Fatigue limit, endurance limit, and fatigue strength are all expressions used to describe property of materials. It is the amplitude or range of cyclic stress that can be applied to the material without causing fatigue failure.

Fail-safe design is design in such a way that there is no single point of failure, and so that when any one part completely fails, it does not lead to catastrophic failure of the entire system.

Fail-safe or fail-secure devices are the ones that, in the event of failure, respond in a way that cause no harm, or at least a minimum of harm, to other devices or danger to personnel. For example, aircraft landing on an aircraft carrier increases the throttle to full power at touchdown, and if the arresting wires fail to capture the plane, it will be able to take off again.

Graceful degradation is the property that enables a system to continue operating properly in the event of the failure of (or one or more defects within) some of its components. If its operating quality decreases at all, the decrease is proportional to the severity of the failure.

Fault tolerant design enables a system to continue its intended operation, possibly at a reduced level, rather than failing completely, when some part of the system fails. The term is most commonly used to describe computer systems designed to continue more or less fully operational with, perhaps, a reduction in throughput or an increase in response time in the event of some partial failure.

\subsection{Finite lifetime concept methods}

Safe-life design (finite lifetime concept or safe-life design practice) is design for a fixed life after which the user is instructed to replace the part with a new one.

Planned obsolescence or built-in obsolescence in industrial design is a policy of planning or designing a product with a limited useful life, so it will become obsolete, that is, unfashionable or no longer functional after a certain period of time.

A disposable product is a product designed for a single use after which it is recycled or is disposed as solid waste. The term often implies cheapness and short-term convenience rather than medium to long-term durability.

\subsection{Damage tolerant design methods or methods of non- destructive testing}

Damage tolerant design instructs the user to inspect the part periodically for cracks and to replace the part once a crack exceeds a critical length. This approach usually uses the technologies of non-destructive testing and requires an accurate prediction of the rate of crackgrowth between inspections. The designer sets some aircraft maintenance checks schedule frequently enough that parts are replaced while the crack is still in the "slow growth" phase.

Methods for non-destructive testing (Non-Destructive Testing - NDT) are a set of methods for finding defects in material and in such a way that materials or devices after testing remain intact, and if there are not defects detected, they can be placed in normal exploitation.

NDT methods are focused on the detection of micro cracks on the surface or below the surface of the element, and to detect defects in inaccessible places when regular visual inspection without tools is conducted. NDT methods are applied to the aircraft itself and individual elements of the aircraft.

The most commonly used methods of NDT are: visual, magnetic, penetrant, radiographic, ultrasonic and eddy current methods.

\subsubsection{Visual inspection}

Visual testing is the oldest and most common form of inspection. It consists of an overview using human eye, a magnifying glass, a light source or special optical devices. The reliability of this method depends on the ability and experience of personnel who must know how to look for structural defects and how to identify an area where such defects are found. 
A visual examination with the help of optical devices can be considered an extension of the human eye. From inaccessible areas, an image on the screen is formed that can be electronically captured, increased, analysed and recorded for future directions.

Basic equipment for the visual inspection is endoscopes. Endoscopes allow the technician to view the interior of the equipment, components or structures that have closed or hidden areas not accessible to ordinary visual inspection.

Endoscopes (flexible borescopes and inflexible fiberscopes) are optical devices with optical probe which can penetrate through small openings to the work area to be tested. These devices have the possibility of strong internal illumination of dark areas to make good visual inspection, photographing or video recording. Their optical system transmits a clear picture of high resolution to the eyepiece or video monitor which is distant, but connected to the device. Eyepiece is used for direct visual inspection or it can be connected to a photographic or video camera.

Videoscope is an electronic version of the optical fiberscope. Instead of the lens at the end of a flexible tube and coil which transmits the image, videoscope has a small video camera and a lens at the end. The camera, which is based on a compact chip technology, sends back a video image to the unit where it is shown on a video monitor. Example of video borescope is given in Fig. 1.

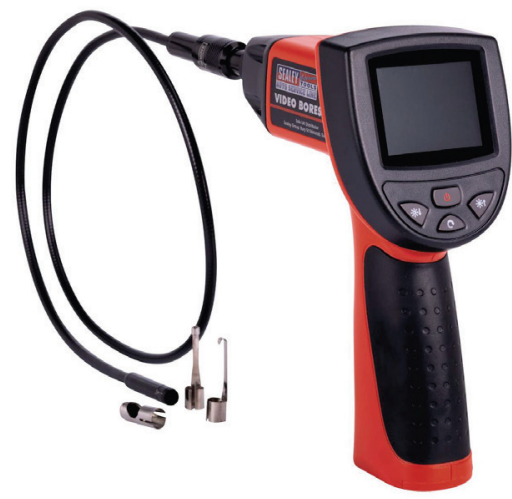

Figure 1 Video borescope [21]

The basic advantages of this method using endoscopes are: it is cheap, it is portable, it gives instant results, and it takes a minimum of special skills and a minimum of preparation.

Disadvantages are that it is only suitable for areas that can be visually detected and it reveals only greater defects.

\subsubsection{Penetrant testing}

Penetrant method (penetrant testing) is used to reveal discontinuities opened towards the surface of the parts made of material that is not porous. The method depends on the ability of liquid to penetrate the discontinuity of the material on which it is applied.

Ordinary penetration method is used for the detection of small cracks or gaps that go up to the surface and that may not be visible under normal visual inspection. Penetration methods can be used in most parts of the structures that are available for its application. Fig. 2 shows how the penetrant method is used to reveal deficiencies in material.

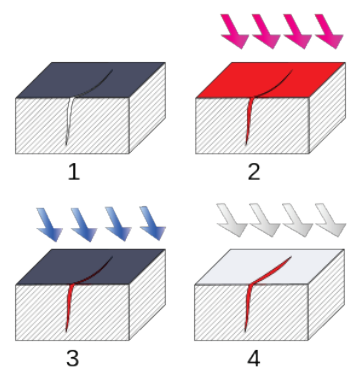

Figure 2 1) section of material with a surface-breaking crack that is not visible to the naked eye, 2) penetrant is applied to the surface, 3) excess penetrant is removed, 4) developer is applied, which renders the crack visible [22]

The process of penetrant testing involves a few basic steps. Part to be tested is first thoroughly cleaned and then a liquid penetrant is applied to the surface. It is left for some time to sit on the surface while the penetrant penetrates the surface discontinuity, if there is any. After that, the penetrant remained on the surface is removed with water, cloth or thinner. Such removal cleans the surface of objects, but allows the penetrant to remain in the discontinuity. Then a developer is applied that works as a blotter and draws penetrant on the surface of objects and creates indication. Subject is inspected in order to detect indications that are visible due to contrast dye between a drawn penetrant and a background surface. After testing the surface is cleaned of residual penetrant and the protective layer is returned.

The advantages of this method are: low cost, portable equipment, it has a high degree of sensitivity; it gives instant results and requires minimum skills for performance and interpretation.

The disadvantages are that it requires a high degree of purity, it can detect only those defects that have a connection with the surface and there are no permanent written test results.

\subsubsection{Ultrasonic testing}

Ultrasonic testing method (ultrasonic inspection) is suitable for the examination of most metals, plastics and ceramics and defects on the surface or below the surface. Ultrasound examination requires that at least one part of surface near the surface to be tested is available. Examination of aircraft structures can be achieved by inducing ultrasonic waves on the object with the contact probe and receiving of reflected waves from that point. Reflection of ultrasonic waves is projected electronically into the tube of oscilloscope and is used to indicate defects. Ultrasonic testing of an aircraft engine is shown in Fig. 3.

Ultrasonic testing method is a method of nondestructive testing that uses high-frequency sound energy (above $20 \mathrm{kHz}$ ) for testing the structural integrity of the material. Ultrasonic waves can spread only in the medium. Precisely this fact is used to detect defects in the tested object. Ultrasonic waves at the medium border, as well as all other types of waves follow the laws of wave motion. For this reason, at the medium border, whether it 
is the wall of the tested object or irregularity, the reflection of ultrasonic waves and/or fracture, diffraction or other interaction between means and transmitted ultrasound energy will occur. Proper interpretation of ultrasound energy obtained from material testing can assess the condition of material and parameters of detected irregularities.

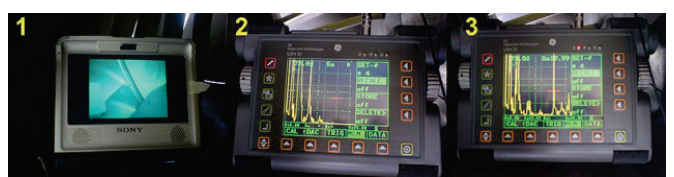

Figure 3 An example of Ultrasonic Testing (UT) on blade roots of a V2500 IAE aircraft engine (step 1: the UT probe is placed on the root of the blades to be inspected with the help of a special borescope tool (video probe), step 2: instrument settings are input, step 3: the probe is scanned over the blade root; an indication to the left of that range indicates a crack) [23]

Ultrasound can be generated in several ways. The most commonly used is piezoelectric effect for production of ultrasonic energy.

If the ultrasonic wave passes through the material, it encounters a defect, it can (depending on the size, location and type of defect) be reflected from surface of defect, or, due to the different angles of reflection, be reduced when returning back to the surface from which it was transmitted. The measurement of these phenomena is the basis of ultrasonic defectoscopy.

Transmitting and receiving ultrasound from and into materials is conducted using a transmitter and receiver or ultrasonic probes, which generate ultrasound waves and convert received ultrasound into an electronic impulse.

Ultrasonic device must allow activation of probes with required electronic impulses and receive electronic impulses from the probe.

Advantages of this method are the following: area thickness of the tested material is very large, tested materials can have very large thickness of the material; devices and accessories are very simple, easily portable and do not take up much space, the risk of device failure is reduced by using modern electronics, which also reduced the weight; handling of devices and equipment poses no danger to the operator; method is very sensitive and detecting defects is fairly simple; and it is possible to test the object from only one side of the tested object.

Disadvantages are: generally cannot leave a permanent document; assessment of defect detected by ultrasound is subject to operator subjectivity and his level of knowledge how to test and properties of the test material; because of the way of testing and assessment results at the point of control, personnel handling devices must, besides greater knowledge, have long practice with the possibility of comparative determination of the character of the detected defects, which is why the introduction of this method takes much longer than any other; ability to detect subsurface defects and defects in objects that have irregular and complicated shapes is relatively weak.

\subsubsection{Magnetic particle inspection}

Magnetic testing method (magnetic particle inspection) is a method used to detect surface and subsurface discontinuities in ferromagnetic materials. Testing is done by inducing a magnetic field in observed part and applying the particles of a dry powder or a liquid suspension of iron oxide. If there is a discontinuity in the material (in the form of cracks, nicks, or inclusions), it leads to increased resistance in magnetic field at the site of the cracks.

If, for example, particles of iron oxide are applied on the surface of material to be tested and if there is a crack perpendicular to the direction of the passage of forces, particles will gather around the cracks. Particles can be seen by colour contrast or fluorescent light under the UV lamp. To obtain the best results of indications, magnetic field forces should be at right angles to the crack, i.e. maximum length of the crack.

Cracks are detected by looking at shapes that are formed on the surface of the particles. Fine discontinuity will diffuse visible indication when formed with a fluorescent magnetic particle. The dry particles are best used on rough surfaces and the supporting equipment.

The simplest devices for magnetic tests are ferroflux devices. These are the generators of DC or AC currents of high strength and low voltage. Example of a horizontal magnetic particle inspection machine is shown in Fig. 4.

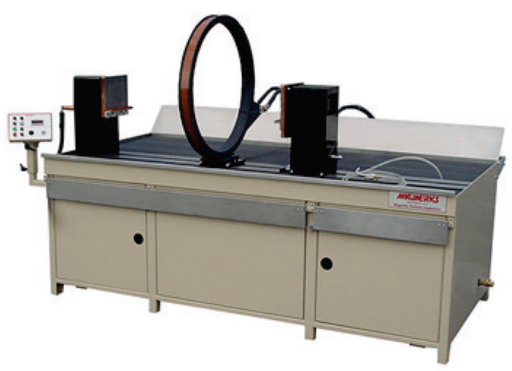

Figure 4 A horizontal MPI machine with a 36 in $(910 \mathrm{~mm})$ coil [24]

The basic advantages of magnetic method are: simplicity of principles and low cost of devices, unless they are automated; easy and simple handling devices; good sensitivity to detect surface and subsurface defects, particularly cracks; interpretation of the results does not require special expertise; the ability to apply on products of complex shapes and with large differences in wall thicknesses (preferred over methods of radiography and ultrasound).

Disadvantages of magnetic method are: it establishes the existence of defects, but not their geometry; deep defects are difficult to detect, reliable detection depth is only a few millimetres and most reliably reveals the defects that have contact with the surface; generally quite slow; interpretation of results depends a lot on the state of the surface of the tested object.

\subsubsection{Radiographic testing}

The radiographic testing of material, material irregularities are obtained in the way that the object of testing is aired with appropriate ionizing radiation. Radiographic testing will therefore show internal and external structural details of all portions of the material. It is a method that is used to check aircraft structure that is unavailable or unsuitable for the use of any other method. 
As a source of radiation $\mathrm{X}$ or gamma rays are to be used to detect objects' interior which is shown in the film.

Radiographic methods differ with respect to: source of ionizing radiation, means for registering the radiation, and way of conducting and/or registering results. Fig. 5 shows principle of radiographic testing method.

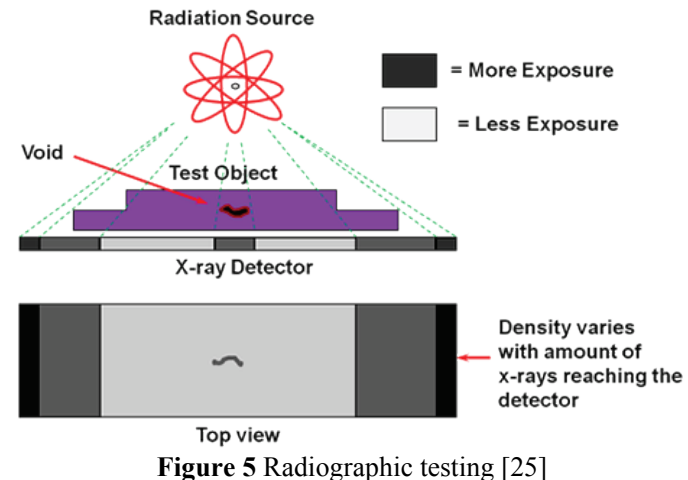

Advantages of film radiography: good visibility of surface, subsurface and internal defects; obtaining of a permanent document (film), which may subsequently determine the level of quality of inspected items; recording and interpretation are widely separated and the review conduct does not require a large number of highly specialized personnel as recording and interpretation can be separated in time; minimal preparation work.

Disadvantages of film radiography: devices to conduct control measures are relatively expensive, and accessories for recording and reviewing films require constant new investments; unsuitable for control of products whose walls show large differences in thickness, certain types of small thickness defects such as cracks transversely to the direction of radiation are very difficult to detect by this method; it may be necessary to drain the fuel from the tank; because of X-ray other staff should be out of the area designated as harmful.

\subsubsection{Eddy current testing}

Eddy current testing is used to detect fractures on the surface or near the surface in most metals. It can be used for aircraft parts or assemblies where the damaged area is accessible to contact probe. Examination is done by inducing eddy currents in the part to be tested and monitoring electronically variations in the induced field.

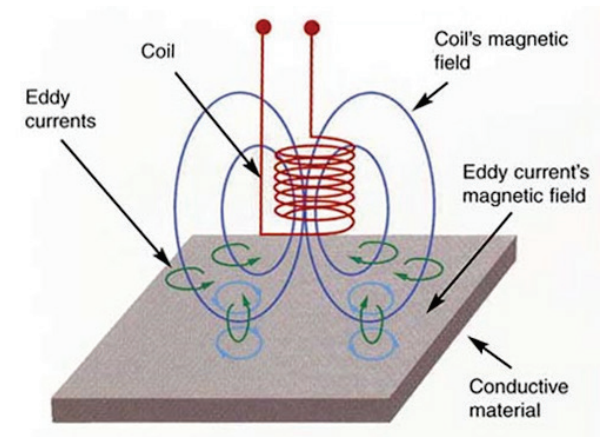

Figure 6 Eddy current testing [26]

Eddy current testing method is a method of nondestructive testing that can detect discontinuities in parts that are electrically conductive. Eddy currents are circular electric currents that are induced in conductive material by an alternating magnetic field, and exhibit properties such as the compressible medium (e.g. air) when encountering an obstacle, such as crack, they are traveling around it, being compressed and getting weak in a similar manner as the air does. Character of observed changes in the field is interpreted as a defect in the material. Eddy current testing method is shown in Fig. 6.

Advantages of this method are the following: tests can be quickly conducted; it is possible to detect defects under a layer of coating (paint, etc.) from 1,5 to $2 \mathrm{~mm}$ and thus save money and time for removal of the same; it is possible to measure the thickness of coatings (paint, etc.) and determine the metallurgical differences; in addition to cracks, in the interior of the tube sediment build-up can be detected; there is a good possibility to determine the size (depth) of damage; it is not necessary to use a contact means.

Disadvantages of this method are: small possibility of finding shallow defects in materials with little wall thickness, and relatively high cost of equipment and probes.

\subsubsection{Low coherence interferometry}

New materials such as polymer composites and ceramics have found a wide variety of applications in modern industries including energy, aviation and infrastructure. This is due to their superior properties as compared to traditional materials. For process enhancement, quality control and health monitoring where these types of materials are used, sophisticated techniques are needed to non-destructively inspect the complex geometries inside the structures produced. Lowcoherence interferometry has been developed as a powerful tool for the cross-sectional imaging of microstructures.

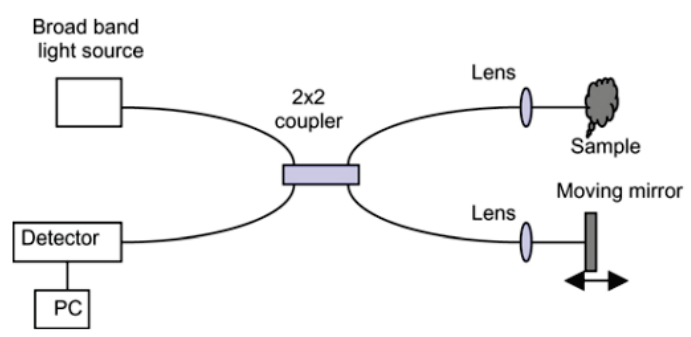

Figure 7 The schematic setup of the low-coherence interferometer [17]

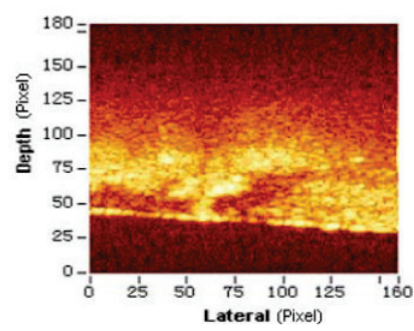

Figure 8 The cross-sectional image for composite material sample [18]

Interferometry uses the principle of superposition to combine waves in a way that will cause the result of their combination to have some meaningful property that is diagnostic of the original state of the waves. Most 
interferometers use light or some other form of electromagnetic wave.

The schematic setup of the low-coherence interferometer is shown in Fig. 7. Obtained crosssectional image for composite material sample is shown in Fig. 8 .

\subsection{Cold expansion methods}

Over the past 40 years, cold expansion processes have impacted fatigue crack mitigation, structural integrity and airworthiness.

In conjunction with improving materials, reducing effect of stress concentration in hole and mitigation of fatigue cracks at holes, was focus in 1960s.

Term "cold working" or as it is later called "cold expansion" usually applies to processes that improve strength and performance via cold work hardening.

The probability of fatigue increases where stresses are concentrated, like sharp bends and fastener holes.

Holes typically magnify the applied stresses by three times. Holes make the metal especially susceptible to fatigue because the hole alters the stress flow and concentrates stress due to cyclic loads.

Many systems have been conceived to offset or mitigate this stress concentration problem in fastener holes.

The most common stress concentrations in mechanically fastened aircraft structures are the ones that cannot be avoided, the fastener holes.

Fatigue cracking can occur only under conditions of fluctuating tensile stresses.

Methods to reduce fatigue problems: thicken the structure locally to reduce stress levels with a structural weight penalty; install interference fit fasteners (props' hole); reduce amplitude of the applied strain; fastener preload or clamp up or bridge hole via interface friction; and induce a compressive hoop pre-stress associated with a cold working process.

The sleeve cold working or pre-stressing system is the one that appears to offer certain advantages in terms of simplicity, flexibility, performance, cost, and minimized skill requirements.

From the early advent of metal structures, surface treatment methods had been devised to improve ageing and durability of holes and surfaces.

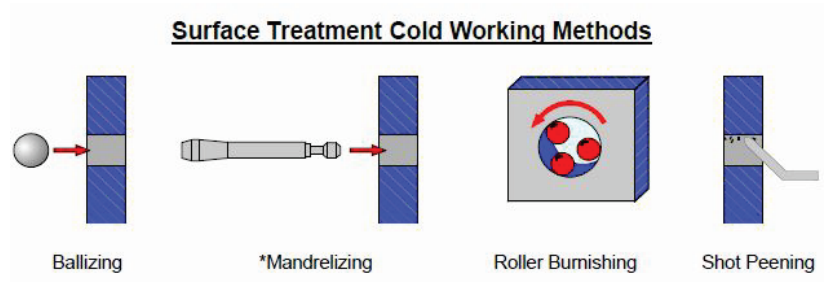

Figure 9 Surface treatment cold working methods [20]

From 1940s to 1950 s the used methods are ballizing, mandrelizing (mandrel only) and broaching, in 1960s there are improved materials, surface treatments or shot peening (Fig. 9), in 1960s interference fit fasteners, in 1970s high interference cold working (Fig. 10), split sleeve cold expansion (Fig. 11), stress coining (ring and pad), in 1980s derivative cold expansion processes, and today ForceMate methods of derivative cold expansion processes.

High Interference Expansion Methods

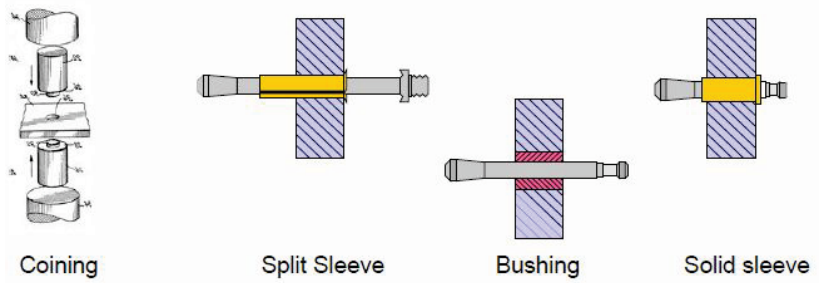

Figure 10 High interference expansion methods [20]

Basic split sleeve cold expansion process is conceptualized. The split sleeve is slipped onto the mandrel, which is attached to the hydraulic puller unit. The mandrel and sleeve are inserted into the hole with the nose-cap held firmly against the work-piece. When the puller is activated, the mandrel is drawn through the sleeve radially expanding the hole.

Advantages (mandrel only) are: it is a one sided process; higher applied expansion; radial expansion; uses lower pull force; there is no damage to hole; and minimal surface upset. The split sleeve, though simple in design, makes the process possible and effective.

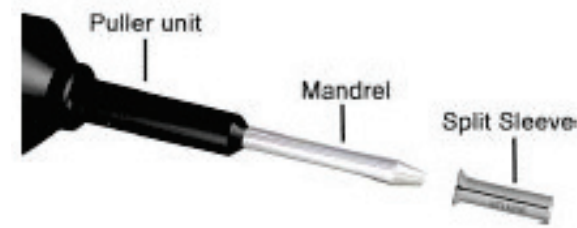

Figure 11 Split Sleeve Cold Expansion [20]

Cold expansion induces a zone of residual compressive stress around and through a hole, typically extends radially at least one radius around hole. Fig. 12 shows induced residual stress distribution.

Hole is effectively "shielded", reducing effective stress intensity factor and therefore the propagation of fatigue cracks. Effect of applied expansion on fatigue life improvement is shown in Fig. 13.

Cold expansion improves fatigue life, durability and damage tolerance of structure.

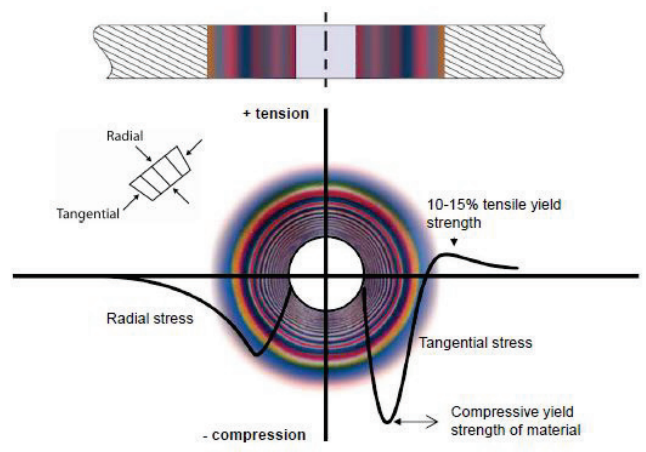

Figure 12 Induced residual stress distribution [20]

Characteristics are: sizes of holes from 0,070 " to over 5,5"; typically applied expansion levels ranging from: $3 \%$ to $5 \%$ aluminium and $5 \%$ to $6 \% \mathrm{Ti}$ and $\mathrm{HS}$ steels; effective in most aerospace materials; and it is one sided process 


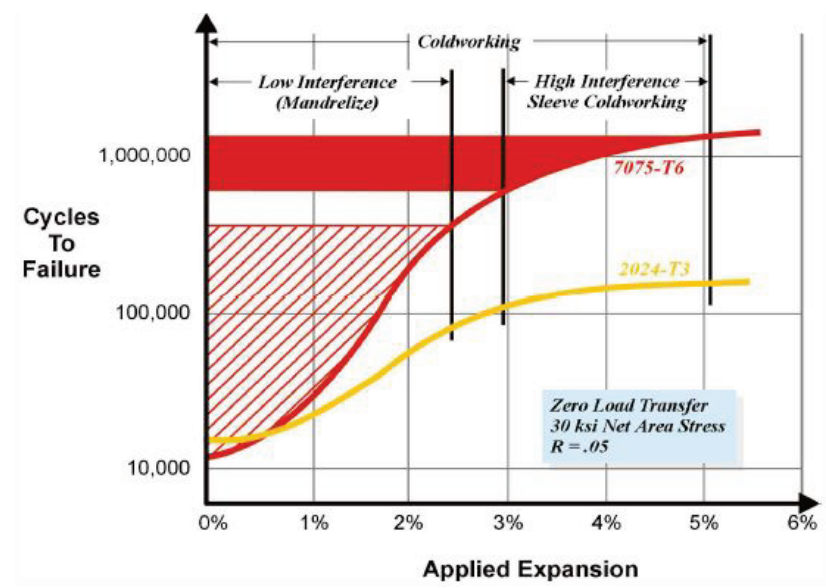

Figure 13 Effect of applied expansion on fatigue life improvement [20]

Fig. 14 shows hole cold expansion effects on fatigue life improvement, weight savings and design optimization. Figs. 15 and 16 show cold expansion effects on fatigue life improvement in aluminium. Fig. 17 shows cold expansion effects on fatigue life improvement in titanium.

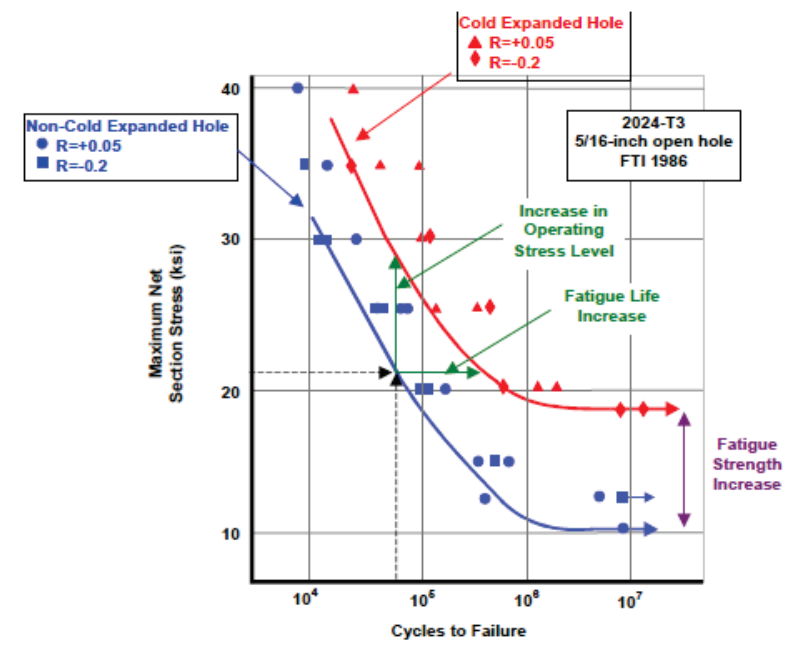

Figure 14 Fatigue life improvement, weight savings and design optimization [20]

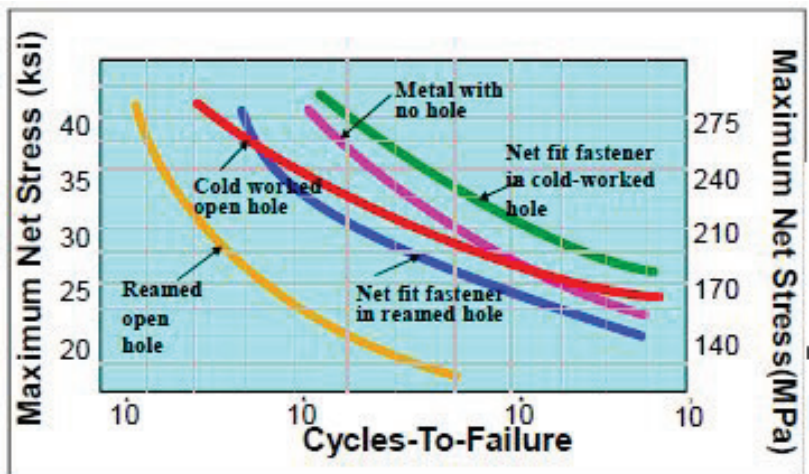

2024-T851 Aluminum

Figure 15 Fatigue life improvement in aluminium [20]

Interference-fit fasteners minimize crack initiation by tensile pre-stressing. Fatigue enhancement is critically dependent on the fit of the fastener. Effect of fastener interference is shown in Fig. 18.
In the split sleeve cold expansion process residual compressive stresses impart fatigue improvement directly into the metal.

\section{5-T6 Aluminum}

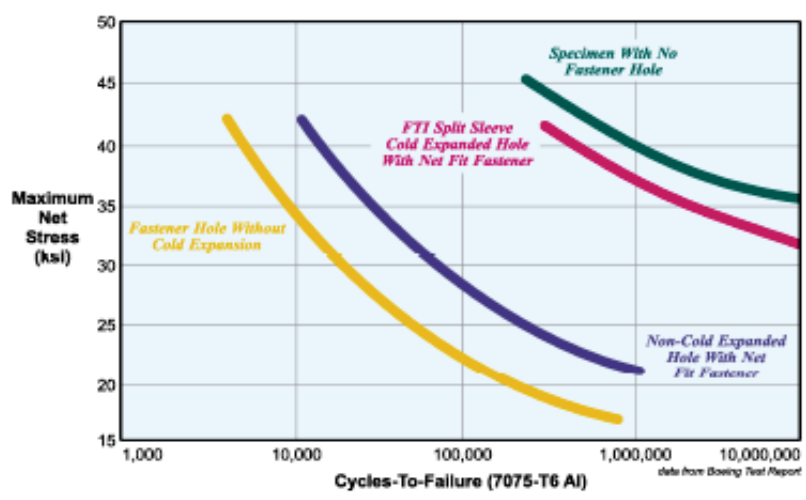

Figure 16 Fatigue life improvement in aluminium [20]

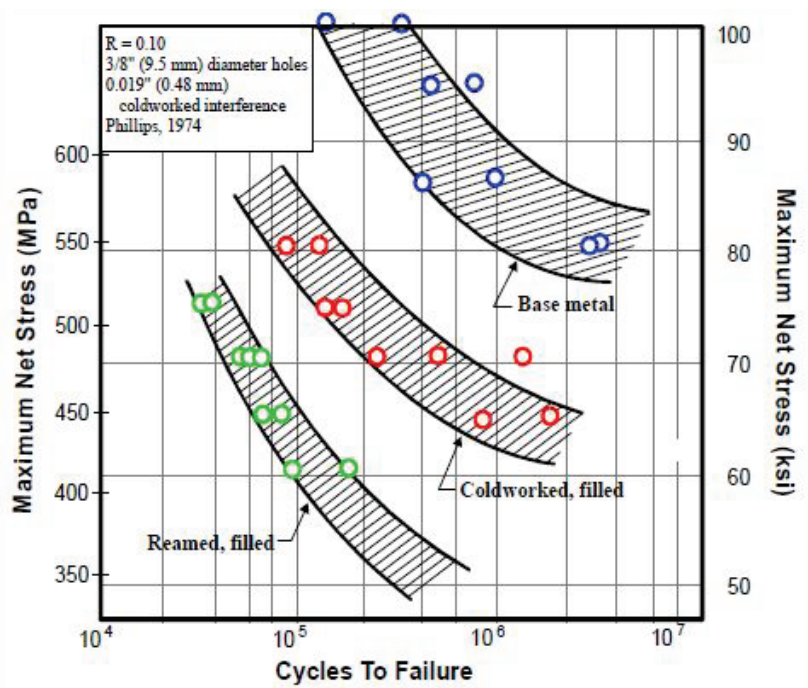

Figure 17 Fatigue life extension in titanium [20]

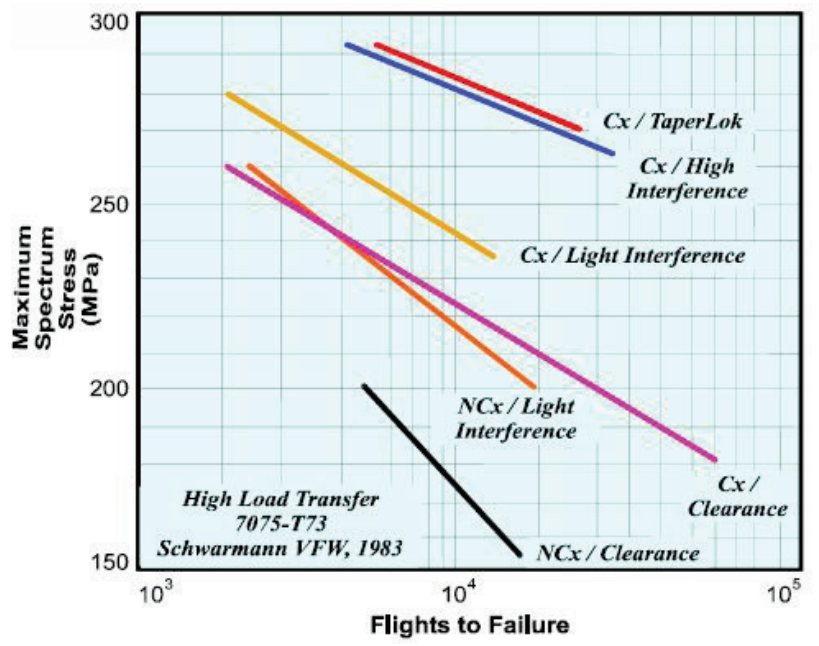

Figure 18 Effect of fastener interference [20]

Cold expansion can increase the damage tolerance life and it has been demonstrated it can completely arrest the growth of small cracks without increasing the thickness (weight) of the structure.

Permanent compressive stresses reduce crack growth and improve damage tolerance of structure: minimize 
crack opening displacement; reduce stress intensity factor range; reduce tensile stress at hole's edge; and it can increase critical crack length for unstable fracture.

Fig. 19 shows effect of cold expansion on crack tip stress intensity. Fig. 20 shows fatigue crack abatement. Fig. 21 shows extended inspection interval with cold expansion.

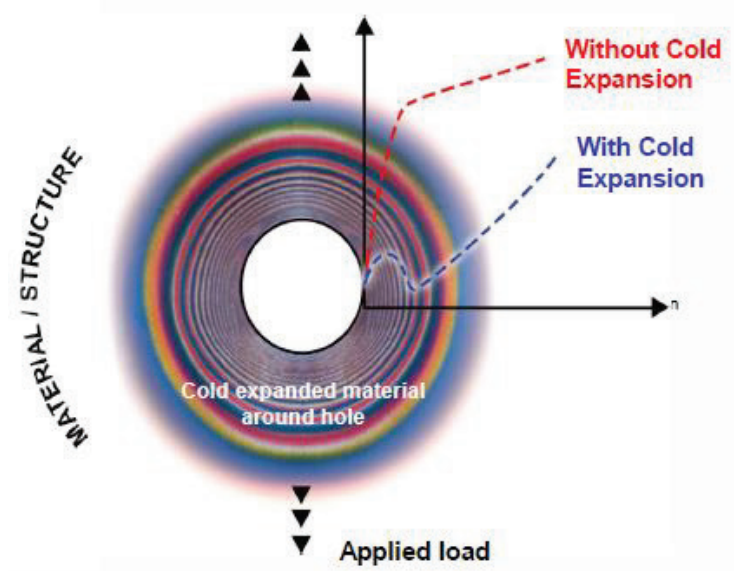

Figure 19 Effect of cold expansion on crack tip stress intensity [20]

Tab. 1 shows crack growth investigations done by various investigators on various materials and it also shows fatigue life improvement.

\begin{tabular}{|c|c|c|c|c|}
\hline Investigator & Spectrum & Material & Initial flaw & $\begin{array}{c}\text { Life } \\
\text { improvement }\end{array}$ \\
\hline Northrop & TAC T-38 & $\begin{array}{c}7075-\mathrm{T} 6 \\
7075-\mathrm{T} 73\end{array}$ & $\begin{array}{c}0,002 \rightarrow \\
0,01\end{array}$ & $5: 1$ \\
\hline Boeing & KC-135 & 7178-T6 & $\begin{array}{c}0,07 \rightarrow \\
0,08\end{array}$ & $4: 1 \rightarrow 15: 1$ \\
\hline $\begin{array}{c}\text { Toor } \\
\text { (Lockheed GA) }\end{array}$ & $\begin{array}{l}\text { Constant } \\
\text { Amplitude }\end{array}$ & 7075-T6 & 0,05 & $3,5: 1$ \\
\hline $\begin{array}{c}\text { Tiffany, } \\
\text { Stewart \& } \\
\text { Moore (USAF) } \\
\end{array}$ & C-5A & 7075-Т6 & $\begin{array}{c}0,05 \rightarrow \\
0,09\end{array}$ & $\begin{array}{c}4: 1 \\
\text { No cold-work } \\
\text { failures }\end{array}$ \\
\hline $\begin{array}{c}\text { Kobler, Huth, \& } \\
\text { Schutz (LBF } \\
\text { Germany) }\end{array}$ & $\begin{array}{l}\text { Constant } \\
\text { Amplitude }\end{array}$ & 2024-Т3 & $\begin{array}{c}0,05 \rightarrow \\
0,23\end{array}$ & $3: 1 \rightarrow 6: 1$ \\
\hline $\begin{array}{c}\text { Hoosen \& } \\
\text { Eidenhoff } \\
\text { (Grumman) }\end{array}$ & $\mathrm{F}-14$ & $\begin{array}{l}\text { Ti-6AL-6V- } \\
2 \text { SN }\end{array}$ & $\begin{array}{c}0,035 \rightarrow \\
0,040\end{array}$ & $10: 1$ \\
\hline $\begin{array}{l}\text { Ozelton \& } \\
\text { Coyle } \\
\text { (Northrop) }\end{array}$ & $\begin{array}{l}\text { Constant } \\
\text { Amplitude }\end{array}$ & $\begin{array}{c}\text { 7050-T7451 } \\
\text { Ti-6AL-6V- } \\
\text { 2SN } \\
\end{array}$ & $\begin{array}{c}0,020 \rightarrow \\
0,120\end{array}$ & $\begin{array}{l}8,6: 1 \rightarrow 1,6: 1 \\
>100: 1 \rightarrow 3: 1\end{array}$ \\
\hline $\begin{array}{l}\text { Petrak \& } \\
\text { Stewart }\end{array}$ & $\begin{array}{c}\text { Constant } \\
\text { Amplitude }\end{array}$ & 7075-T6 & $\begin{array}{c}0,030 \rightarrow \\
0,100\end{array}$ & $>100: 1 \rightarrow 2: 1$ \\
\hline $\begin{array}{l}\text { FTI (Fatigue } \\
\text { Technology) }\end{array}$ & & $\begin{array}{l}7075-\mathrm{T} 6 \\
2024-\mathrm{T3}\end{array}$ & $0,05 \rightarrow 0,1$ & $\begin{array}{c}>100: 1 \rightarrow 2: 1 \\
6: 1 \rightarrow 4: 1\end{array}$ \\
\hline
\end{tabular}

Cold expansion will often extend initial inspection threshold beyond the original economic life of the structure.

Cold expansion can: increase the fatigue life of a hole or joint; provide a solution independent of fastener fit or hole quality; reduce or arrest crack growth; enhance damage tolerance; extend inspection thresholds; provide terminating repair action; mitigate design or repair consequences; facilitate structural weight reduction; be effective in tensile and compressive load environments; do all mentioned above without changing weight, stiffness or dynamic response of the structure; and present the foundation of so many derivative products or processes.

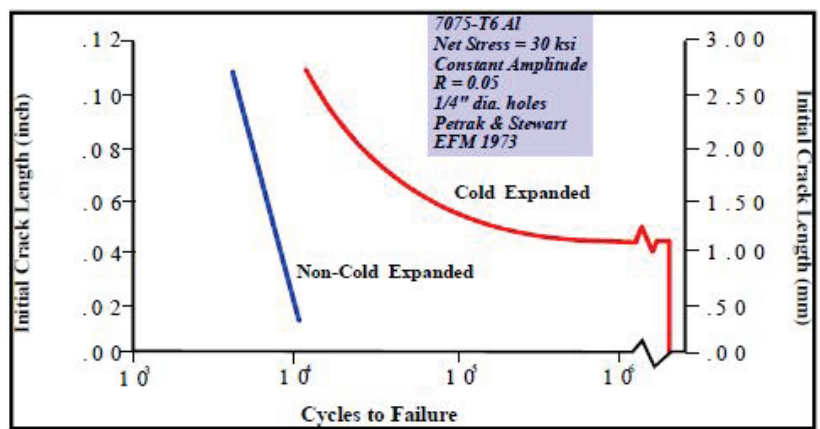

Figure 20 Fatigue crack abatement [20]

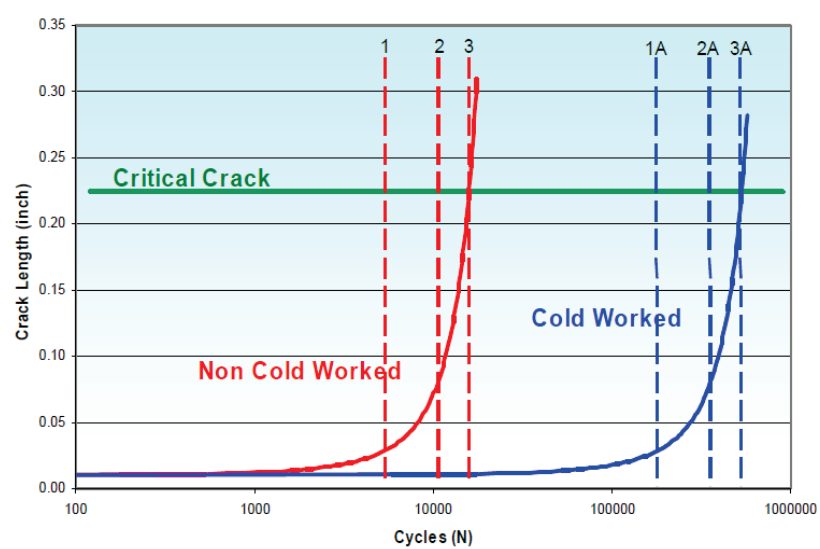

Figure 21 Extended inspection interval with cold expansion (with initial 0.005 " flaw) [10]

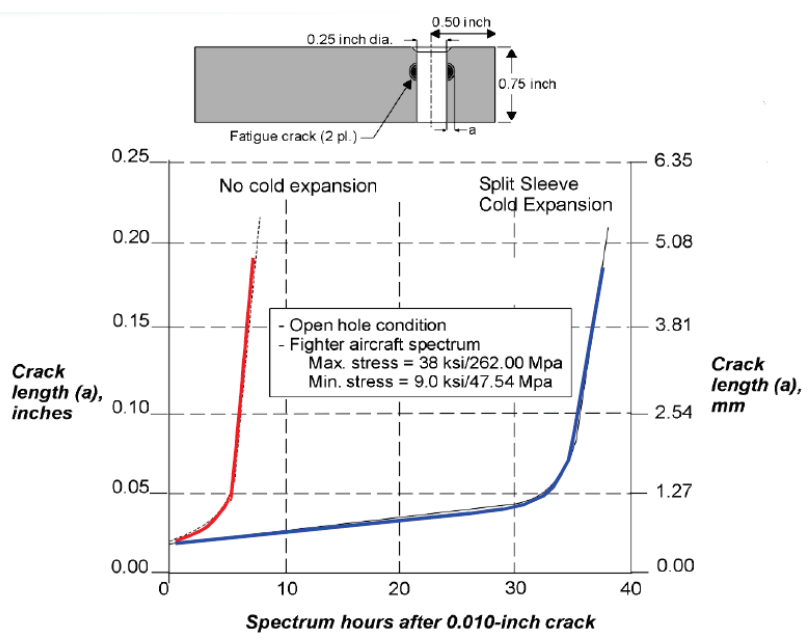

Figure 22 Damage tolerance benefits (fighter aircraft study) [20]

\subsection{BITE concept}

All modern transport aircraft today have some form of permanent monitoring of technical condition which is integrated on the aircraft (On-board Maintenance Systems). For mechanical components it means that there are sensors placed that continuously measure a parameter of the system by which the technical condition can be evaluated. Examples are sensors that measure pressure, temperature, vibration, shifts, etc. These systems allow the detection of defects during operation and are called BITE (Built In Test Equipment).

The BITE is characterized primarily as a passive error management and diagnosis built into airborne systems to support the maintenance process. Built-in test equipment refers to multi-meters, oscilloscopes, discharge probes, 
and frequency generators that are provided as part of the system to enable testing and perform diagnostics.

The term BITE often includes: detection of defects, placement of the defect (how the system actively responds to the defect) and annunciation or logging of the defect to warn of possible effects and/or aid in troubleshooting the affected equipment.

Its functionalities are: analysis of failure monitoring results, reporting and memorization of failures and management of tests. Fig. 23 shows BITE concept on the Airbus 320.

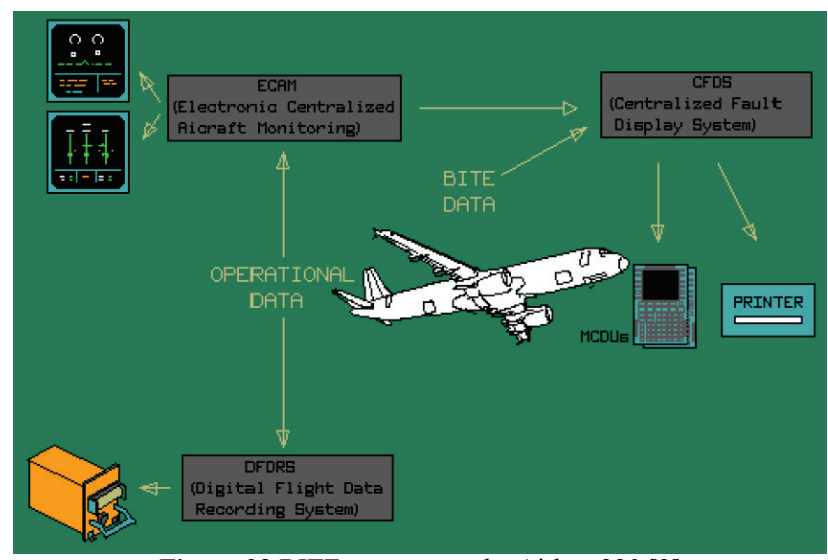

Figure 23 BITE concept on the Airbus 320 [2]

\subsection{SHM concept}

The process of implementing a damage detection and characterization strategy for engineering structures is referred to as Structural Health Monitoring (SHM). Here damage is defined as changes to the material and/or geometric properties of a structural system, including changes to the boundary conditions and system connectivity, which adversely affect the system's performance. The SHM process involves the observation of a system over time using periodically sampled dynamic response measurements from an array of sensors, the extraction of damage-sensitive features from these measurements, and the statistical analysis of these features to determine the current state of system health.

For long term SHM, the output of this process is periodically updated information regarding the ability of the structure to perform its intended function in light of the inevitable aging and degradation resulting from operational environments. After extreme events, such as earthquakes or blast loading, SHM is used for rapid condition screening and aims to provide, in near real time, reliable information regarding the integrity of the structure.

Monitoring of the structure status (Structural Health Monitoring) is a concept of system for continuous monitoring the technical condition of the aircraft structure. SHM will be a key technology for maintaining the integrity of the aircraft structure in the future. The basic principle lies in creating a reliable non-destructive technology that would be an integral part of the aircraft structure. Sensors mounted on the plane would detect the defect in time and further take action. SHM sensors will be able to detect: fatigue, hidden cracks, weakened joints, erosion, corrosion, cracks in the structure, etc. The integrated network, except for structural elements, will oversee even other systems on the aircraft (hydraulic, electronic, and electric).

Positive SHM features in comparison to conventional NDT: sensors are placed on the plane to oversee the entire structure; physical access to equipment or human is not needed to access areas to be tested; inspection of hazardous areas shall be carried out in a safe manner; inspection is fully automated; at the same time it examines several areas; and the results of the testing have no impact of the human factor. Fig. 24 shows how SHM can be arrayed through the aircraft similar to the human nervous system.

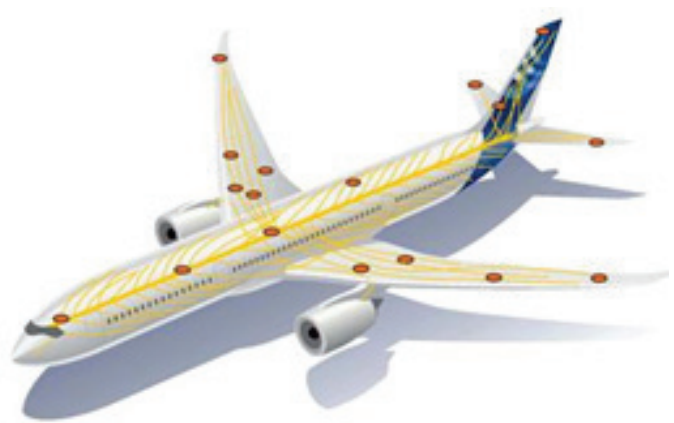

Figure 24 Structural health monitoring (SHM) systems can be arrayed in similar fashion to the human nervous system, with sensors concentrated in key areas where loads are highest [27]

\subsection{Methods to detect corrosion fatigue}

Recent research identifies interactions between corrosion and fatigue such that the presence of corrosion accelerates damage due to fatigue; thereby further reducing the total service life of an aircraft.

For detecting corrosion in aircraft structures combined NDT methods are used. Corrosion is detected in the material specimen with techniques like guided wave, eddy current or ultrasonic pulse-echo as shown in Fig. 25.

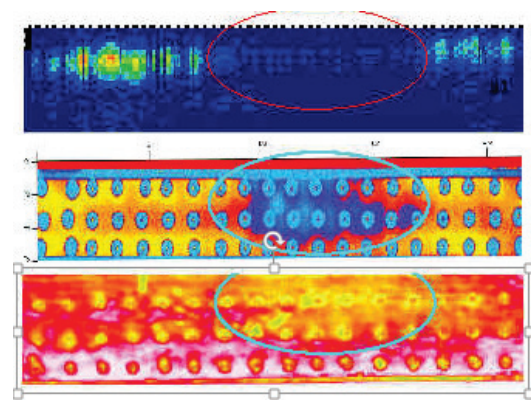

Figure 25 Corrosion inspection [29]

\section{Conclusion}

Fatigue occurs when a material is subjected to frequent loading and unloading. If the loads are above a certain threshold, microscopic cracks will begin to form, eventually a crack will reach a critical size, it will propagate suddenly, and the structure will fracture. The structure is tested to assess the situation and, if necessary, take corrective actions to prevent the occurrence of failures during operation. Accidents caused by fatigue are presented in the paper. De Havilland Comet 1 aircraft 
accidents were a "wake up call" to the catastrophic effects of material fatigue. Hence, different methods are developed to detect and prevent fatigue of material in aircraft structures. The most important and most commonly used methods are infinite lifetime concept methods, finite lifetime concept methods, non-destructive testing methods, cold expansion methods, methods using built-in testing equipment and structural health monitoring methods. Infinite lifetime concept is a design to keep stress below threshold of fatigue limit. Finite lifetime concept or safe-life design practice is a design for a fixed life after which the user is instructed to replace the part with a new one. Methods for non-destructive testing is a set of methods for finding defects in material and in such a way that materials or devices after testing remain intact, and if there are not defects detected, they can be placed in a normal exploitation. The most commonly used methods of non-destructive testing are: visual, magnetic, penetrant, radiographic, ultrasonic, eddy current methods and low-coherence interferometry. Cold expansion induces a zone of residual compressive stress around and through a hole. Hole is effectively shielded and protected, reducing effective stress intensity factor and therefore the propagation of fatigue cracks. It improves fatigue life, durability and damage tolerance of structure. All modern transport aircraft today have some form of permanent monitoring of technical condition which is integrated on the aircraft. These systems allow detection of defects during operation and are called built-in test equipment. The process of implementing damage detection and characterization strategy for engineering structures is referred to as structural health monitoring. Fatigue cracks and corrosion can be detected by using ultrasonic pulseecho, eddy current or guided and surface wave inspection techniques.

\section{$5 \quad$ References}

[1] Pyles, R. A. Aging Aircraft USAF Workload and Material Consumption Life Cycle Patterns. Rand, USA, 2003.

[2] Bazijanac, E. Tehnička eksploatacija i održavanje zrakoplova. Fakultet prometnih znanosti, Sveučilište u Zagrebu, Zagreb, 2007.

[3] Stephens, R. I.; Fatemi, A.; Stephens, R. R.; Fuchs, H. O. Metal Fatigue in Engineering. $2^{\text {nd }}$ ed. Wiley-Interscience Publication, Canada, 2001.

[4] Hertzberg, R. W. Deformation and Fracture Mechanics of Engineering Materials. Wiley-Interscience Publication, Canada, 1996.

[5] Anderson, T. L. Fracture Mechanics Fundamentals and Applications. 3rd ed. Taylor and Francis Group, 2005.

[6] Suresh, S. Fatigue of Materials. $2^{\text {nd }}$ ed. Cambridge University Press, UK, 2004.

[7] Schijve, J. Fatigue of Structures and Materials. $2^{\text {nd }}$ ed. Springer, 2009. DOI: 10.1007/978-1-4020-6808-9

[8] ATSB Transport Safety Report. // How Old is Too Old? The impact of ageing aircraft on aviation safety. Canberra City: ATSB. 2007.

[9] Giurgiutiu, V.; Zagrai, A.; Bao, J. Damage Identification in Aging Aircraft Structures with Piezoelectric Wafer Active Sensors. // Journal of Intelligent Material Systems and Structures, Vol. 15, September/October, 1045-389X (2004). DOI: $10.1177 / 1045389 \times 04038051$

[10] Zuo J. Z.; Kermanidis, A. T.; Pantelakis, S. G. Strain energy density prediction of fatigue crack growth from hole of aging aircraft structures. // Elsevier, Theoretical and
Applied Fracture Mechanics. 38, (2002), pp. 37-51. DOI: 10.1016/S0167-8442(02)00079-4

[11] O’Donoghue, P. E.; Atluri, S. N.; Pipkins, D. S. Computational strategies for fatigue crack growth in three dimensions with application to aircraft components. // Engineering Fracture Mechanics. 52, 1(1995), pp. 51-64. DOI: 10.1016/0013-7944(94)00329-G

[12] Carpenter, M. Managing the Fleet: Materials Degradation and its Effect on Aging Aircraft. // The AMPTIAC, Advanced Material and Processes Technology. 5, 4(2001).

[13] Gu, L.; Kasavajhala, A. M. M.; Zhao, S. Finite element analysis of cracks in aging aircraft structures with bonded composite-patch repairs. // Composites. Part B 42, (2011), pp. 505-510. DOI: 10.1016/j.compositesb.2010.11.014

[14] Kuen Y. L.; Andrey V. S. Probabilistic Approach to Damage Tolerance Design of Aircraft Composite Structures. // Journal of Aircraft. 44, 4(2007).

[15] Pitt, S.; Jones, R. Multiple-site and Widespread Fatigue Damage in Aging Aircraft. // Engineering Failure Analysis. 4, 4(1997), pp. 237-257. DOI: 10.1016/\$1350-6307(97)00020-4

[16] Goranson, U. G. Fatigue issues in aircraft maintenance and repairs. // International Journal of Fatigue. 20, 6(1997), pp. 413-431. DOI: 10.1016/S0142-1123(97)00029-7

[17] Guiju Song, G.; Harding, K.; Zheng, J.; Herd, K. Low coherence interferometry for industrial inspection. // SPIE Newsroom, (2006). DOI: 10.1117/2.1200603.0130

[18] Wiesauera K.; Pircherb M.; Götzingerb E. En-face scanning optical coherence tomography with ultra-high resolution for material investigation. // Optics Express. 13, 3(2005), pp. 1015-1025. DOI: 10.1364/OPEX.13.001015

[19] Lincoln, J. W. Managing the Ageing Aircraft Problem. // RTO AVT Specialists' Meeting on Life Management Techniques for Ageing Air Vehicles / Manchester, 2001, RTO-MP-079(II)

[20] Reid, L. Hole Cold Expansion, the Fatigue Mitigation Game Changer of the Past 50 Years. // International Fatigue 2014 Congress / Melbourne, 2014

[21] http://www.toolstop.co.uk/components/com_virtuemart/sho p_image/product/VS8196.V2.jpg (05.01.2015)

[22] http://upload.wikimedia.org/wikipedia/commons/thumb/3/3 b/Ressuage principe $2 . \mathrm{svg} / 250 \mathrm{px}$ Ressuage_principe_2.svg.png (05.01.2015)

[23] http://upload.wikimedia.org/wikipedia/commons/5/59/NDT test_of_an_V2500_engine_blade_route.jpg (05.01.2015)

[24] http://upload.wikimedia.org/wikipedia/commons/thumb/2/2 a/New_Wet_Horizontal.jpg/200pxNew_Wet_Horizontal.jpg (05.01.2015)

[25] http://www.iprt.iastate.edu/sites/default/files/nde/radiograp hic/ri_work_cartoon.png (05.01.2015)

[26] https://www.ndeed.org/GeneralResources/MethodSummary/ET1.jpg (05.01.2015)

[27] http://d2n4wb9orp1vta.cloudfront.net/resources/images/cdn /cms/0908hpc-smart2.jpg (05.01.2015)

[28] Abdel-Latif, A. M. An Overview of the Applications of NDI/NDT in Engineering Design for Structural Integrity and Damage Tolerance in Aircraft Structures. In Damage and Fracture Mechanics, 2009, pp. 93-100.

[29] Brassard, M.; Chahbaz, A.; Pelletier, A. Combined NDT Inspection Techniques for Corrosion Detection of Aircraft Structures. Tektrend International, NDT Technology Development Group, Structures, Materials and Propulsion Laboratory, Institute for Aerospace Research, National Research Council Canada2000. http://www.ndt.net/article/ wendt00/papers/idn534/idn534.htm (05.01.2015) 


\section{Authors' addresses}

prof. dr. sc. Željko Marušić,

Faculty of Traffic and Transport Sciences

Vukelićeva 4, 10000 Zagreb, Croatia

Dajana Bartulović, mag. ing. traff.

Faculty of Traffic and Transport Sciences

Vukelićeva 4, 10000 Zagreb, Croatia

mr. sc. Branko Maković

Faculty of Traffic and Transport Sciences

Vukelićeva 4, 10000 Zagreb, Croatia 